\title{
Alexithymia Profile in Relation to Negative Affect in Parents of Autistic and Typically Developing Young Children
}

\author{
Elisa Leonardi ${ }^{1}$, Antonio Cerasa ${ }^{1,2} \mathbb{D}$, Francesca Isabella Famà ${ }^{1}$, Cristina Carrozza ${ }^{1}$, \\ Letteria Spadaro $^{1}$, Renato Scifo ${ }^{3}$, Sabrina Baieli ${ }^{3}$, Flavia Marino ${ }^{1}$, Gennaro Tartarisco ${ }^{1}$, \\ David Vagni ${ }^{1}$, Giovanni Pioggia ${ }^{1, \dagger}$ and Liliana Ruta ${ }^{1, *, \dagger}$ \\ 1 Institute for Biomedical Research and Innovation (IRIB), National Research Council of Italy, \\ 98164 Messina, Italy; elisa.leonardi@istitutomarino.it (E.L.); antonio.cerasa@irib.cnr.it (A.C.); \\ francescaisabella.fama@istitutomarino.it (F.I.F.); cristina.carrozza@istitutomarino.it (C.C.); \\ spadarolia@gmail.com (L.S.); flavia.marino@irib.cnr.it (F.M.); gennaro.tartarisco@irib.cnr.it) (G.T.); \\ david.vagni@irib.cnr.it (D.V.); giovanni.pioggia@irib.cnr.it (G.P.) \\ 2 S. Anna Institute and Research in Advanced Neurorehabilitation (RAN), 88900 Crotone, Italy \\ 3 Centre for Autism Spectrum Disorders, Child Psychiatry Unit, Provincial Health Service of \\ Catania (ASP CT), 95100 Catania, Italy; renato.scifo@aspct.it (R.S.); sabrina.baieli@aspct.it (S.B.) \\ * Correspondence: liliana.ruta@irib.cnr.it \\ + These Authors contributed equally to the study.
}

Received: 25 May 2020; Accepted: 27 July 2020; Published: 29 July 2020

\begin{abstract}
In our study, we explored the construct of alexithymia in parents of children with and without ASD using a multi-method approach based on self-rated and external rater assessment. We also assessed the level of self-report measures of negative affect states such as trait anxiety and depression, and investigated the correlation between the alexithymia construct, trait anxiety, and depression within the broader autism phenotype (BAP). A total sample of 100 parents ( 25 mothers and 25 fathers in each group) were administered the TAS-20 and the TSIA to measure self-reported and observer-rated alexithymia traits, as well as self-report measures of anxiety and depression. Study results showed that the TSIA but not the TAS-20 was able to detect significant group differences in alexithymia traits among parents of children with and without ASD, with parents of ASD children displaying significantly higher levels of alexithymia. Furthermore, differently from the TAS-20, no significant correlations between the TSIA and measures of anxiety and depression were detected. Taken together, our results suggest the importance of using multi-method approaches to control for potential measurement bias and to detect psychological constructs such as alexithymia in subclinical samples such as parents of children with ASD.
\end{abstract}

Keywords: autism; alexithymia; anxiety; depression; TAS-20; TSIA; parents; broader autism phenotype

\section{Introduction}

Alexithymia literally means "absence of words for emotions". It is a personality construct, normally distributed in the general population [1,2], characterized by deficits identifying and describing one's own emotions and feelings, problems distinguishing between feelings and bodily sensations of emotional arousal, lack of fantasy, externally oriented cognitive style, and impairment in cognitively mapping their feeling states onto internal bodily responses [3-6]. Difficulties in emotional awareness may have a negative impact on subjective emotion regulation [7] and, in turn, may compromise the understanding of others' emotions, giving rise to problems in social interaction. It has been reported, indeed, that individuals with alexithymia show difficulties distinguishing and appreciating emotions 
expressed by others, and consequently, they are likely to show nonempathic and idiosyncratic socio-emotional responses [8]. Deficits in empathy, specifically in the cognitive component of recognizing and understanding others emotions, have also been reported as one of the distinctive features of autism spectrum disorders (ASD) [9-13], a neurodevelopmental condition characterized by socio-communicative impairments and restricted and repetitive patterns of behaviors and interests [14]. A significant association between ASD and alexithymia has been reported, with at least half of individuals with ASD experiencing co-occurring alexithymia [15-19]. The interrelationship between the two conditions is complex, and it is still debated whether alexithymia and ASD share common etiological roots or if, instead, alexithymia is a symptomatological manifestation within the ASD neuropsychological functioning [20]. Some broad genetic and neurobiological overlapping between the two conditions have been reported, including the involvement of the serotonin and oxytocin systems, and brain areas related to emotion processing, specifically the amygdala, cingulate, and prefrontal cortex [21]. It has been suggested that a common genetic vulnerability between autism and alexithymia could lead to atypical brain networks, associated in turn with different behavioral patterns that manifest themselves mainly with symptoms of alexithymia, autism, or both [22,23]. At the behavioral level, the intersection between alexithymia and ASD is equally controversial and questions the role of alexithymia in relation to emotion recognition and interoception (the ability to interpret the internal state of the body). Indeed, the abilities to perceive one's own emotions and bodily signals are closely interrelated in social-emotional development [24]. Some studies, comparing individuals with and without ASD on alexithymia, have found that alexithymia, rather than autism per se, predicts difficulties in facial emotion recognition [17], while other evidence in nonclinical samples reported that autism traits more than alexithymia were a stronger predictor of atypical empathy [25]. In relation to interoception, across clinical and nonclinical samples, alexithymia, but not autism, has been associated with impaired interoception $[23,24]$. Furthermore, alexithymia associated traits have also been reported in relatives of individuals with ASD [26] who show subclinical autism traits, reported as the broader autism phenotype (BAP) [27-31]. The BAP is characterized by below the diagnostic threshold social and cognitive deficits, restricted behavior patterns, ASD-like personality characteristics, and psychiatric difficulties in relatives of autistic individuals [28-37]. Furthermore, higher levels of alexithymia in fathers of children with ASD were related to higher severity on the repetitive behavior domain in their children [38]. The most widely used questionnaire to evaluate alexithymia is the Toronto Alexithymia Scale (TAS-20) [39]. The TAS-20 is a self-report measure consisting of 20 items rated on a five-point Likert scale. The higher the score on the TAS-20, the greater the alexithymia traits. Although consistent empirical evidence over the past 25 year period has confirmed the reliability and validity of the TAS-20 to tap into the alexithymia construct [40], some concerns about applying a self-report measure to individuals who have difficulties identifying their own emotional states and lack the appropriate insight on this impairment, have been raised. Self-assessment of the interoceptive deficit in alexithymia would, in fact, imply a self-reliance bias being that the main characteristic of alexithymia is exactly the absence of recognition of one's feelings and bodily sensations [19,41-43]. Another shortcoming of the TAS-20 is that the measure does not include the dimension of the imaginative processes, which represents one of the facets of the complex alexithymia construct. Furthermore, scores at the TAS-20 have been correlated with negative affect states, particularly depression and anxiety. This association may be partially explained by a neuropsychological overlap between these dimensions, being that impairment in interoception is frequently associated with negative affect [44], but might also be related to a negativity response bias due to the self- report nature of the TAS-20 [45-47]. To overcome this limitation, in 2006, Bagby, Taylor, and Parker developed the Toronto structured interview for Alexithymia (TSIA) [48], a structured interview consisting of 24 questions and carried out by an external examiner who scores the items based on the individual responses across four core domains such as difficulty identifying feelings (DIF), difficulty describing feelings (DDF), externally oriented thinking (EOT), and imaginal processes (IMP). Several studies have confirmed the internal and convergent validity as well as cultural stability of the TAS-20 and the TSIA in nonclinical populations, as well as 
clinical patients, and have suggested that the TSIA is able to more reliably assess the "fantasy" facet of the alexithymia construct and to better disentangle negative affect states such as depression and anxiety that may partially overlap with the alexithymia construct [48-53].

To the best of our knowledge, the only study assessing alexithymia in family members using the TSIA was conducted in parents of anorexic daughters [54], reported significantly higher levels of alexithymia using the observer-rated measure as compared to the self-report measure in parents of the clinical group. Also, as far as we are aware, no studies assessing the alexithymia profile through both self-report and interviewer-administered measures in relatives of ASD individuals have been conducted. Hence, in our study, we used both the TAS-20 and the TSIA to investigate alexithymia in parents of children with and without ASD. Furthermore, since it has been demonstrated an association between alexithymia as measured by the TAS-20 and negative affect states, a secondary goal of the study is to explore the association between both self-report and rater-assessed alexithymia scores and measures of depression and trait anxiety. Previous findings have reported, in fact, significantly higher self-reported levels of trait anxiety and depression symptoms in parents of children with ASD [55-60] and it may be relevant to investigate the overlapping alexithymia construct in relation to these dimensions within the BAP trying to disentangle potential biases related to the administration method.

We expect that parents of ASD children, compared to parents of typically developing children, present higher levels of alexithymia at both the TAS-20 and the TSIA, and that the TSIA, in particular, will be able to keep aside co-occurrent traits of depression and anxiety.

\section{Methods}

\subsection{Participants}

Parents were enrolled and tested in the context of an ongoing study on young children with and without ASD, aged between 3 and 6 years of age, both males and females ( $30 \%$ females in the ASD group and $48 \%$ females in the TD group). Parents of children with ASD were recruited and tested at the clinical facilities of the Institute for Research and Innovation in Biomedicine of the National Research Council of Italy (IRIB-CNR) in Messina and at the Centre for Autism Spectrum Disorders, Child Psychiatry Unit, Provincial Health Service (ASP-CT) in Catania, Italy. Parents of typically developing children (TD) were recruited and tested in three different mainstream nursery schools and primary schools in Messina. Inclusion criteria in both the ASD and TD parent groups were: (1) biological parents; (2) native Italian speakers; (3) between the age of 25 and 55 years. Specific inclusion criterion in the ASD parent group was having a child with a confirmed clinical diagnosis of ASD according to the Diagnostic and Statistical Manual of Mental Disorders, Fifth Edition [14], while exclusion criteria in the TD parents group were having a child with a clinical diagnosis of neurodevelopmental conditions (such as language and/or motor delay, ADHD, etc.) and a family history of intellectual disabilities, language delay and ASD. A total sample of 112 parents were recruited. According to the inclusion and exclusion criteria, 12 parents (8 parents in the TD group and 5 parents in the ASD group) were excluded for the following reasons: four couples of parents ( 2 couples in each group) were adoptive parents; two couples of parents of TD children had a first degree relative with ASD; one parent (mother) in the TD group presented a mild intellectual disability; one parent (mother) in the ASD group was a foreigner and had significant difficulties with understanding written and spoken Italian language and finally 4 couples of parents ( 3 couples in the TD group and 1 couple in the ASD group) who initially agreed to participate, subsequently refused to contribute to the study. A final sample of 50 parents ( 25 mothers and 25 fathers) of ASD children and 50 parents of TD children ( 25 mothers and 25 fathers) were fully tested and analyzed in the study.

The study received ethical clearance by the Ethics Committees of CNR (ethical clearance, 01.08.2018) and ASP-CT (Prot. N. 498), respectively, and all the caregivers signed an informed consent to participate in the study. 


\subsection{Measures and Procedures}

All enrolled subjects completed the following neuropsychological assessment battery: (1) the State Trait Anxiety Inventory-Form Y (STAI-Y), a self-report questionnaire which consists of 20 questions scored on a 4-point Likert-type scale, ranging from 1 to 4 (from "almost never" to "almost always"). The total score at the STAI-Y ranges from 20 to 80 , with scores $>40$ indicating above-average levels of anxiety. (2) The Beck Depression Inventory (BDI-II) is a self-report questionnaire with 21 items, rated on a 4-point scale from 0 to 3 , based on the diagnostic criteria for depressive disorders. Inventory cutoffs are: 0-13: minimal depression, 14-19: mild depression, 20-28: moderate depression, and 29-63: severe depression [61,62]; (3) The Toronto Alexithymia Scale (TAS-20) [39] is a self-report scale comprised of 20 items. Each item is rated on a five-point Likert scale ranging from 1 ("strongly disagree") to 5 ("strongly agree"). The TAS-20 is a reliable and valid measure of emotion processing in adults and includes a total score and three subscales: Difficulty Identifying Feelings (DIF), Difficulty Describing Feelings (DDF), and Externally-Oriented Thinking (EOT). The empirically derived cutoff score of 61 is used for identifying individuals with "high" versus "low" alexithymia. (4) The Toronto Structured Interview for Alexithymia (TSIA) is a structured interview with prompts and probes which incorporates the same three subscales included in the TAS-20 (DIF, DDF, and EOT, respectively), and an extra subscale investigating Imaginal Processes (IMP). The TSIA consists of 24 items, six items for each of the four salient facets of the alexithymia construct; (5) the "Reading the Mind in the Eyes" Test Revised (Eyes Test) [63]. In the Eyes Test, the participant is presented with a series of 36 black and white photographs of the eye-region of different actors and actresses and is asked to choose which of four words best describes what the person in the photograph is thinking or feeling. We implemented the test on an iPad tablet 9.7 in and collected both accuracy (number of correct answers) and reaction time (RT = length of time taken to answer in seconds); (6) the Wechsler Abbreviated Scale of Intelligence Second Edition (WASI-II) [64] to assess the intelligent quotient (IQ) in all the participants. All questionnaires were administered in a standardized way and in the same sequence to all participants. Assessment administration took about $2 \mathrm{~h}$ and was split into two sessions over two consecutive days. In the first session, participants filled in the TAS-20, the STAI-Y and the BDI-II, while during the second visit, the TSIA and the WASI-II were administered by an experienced clinical neuropsychologist (E.L.), specially trained on the administration procedures and scoring of the measures.

\subsection{Statistical Analysis}

Statistical analyses were performed using SPSS Version 23.0. Kolmogorov-Smirnov test was carried out and confirmed the assumptions of normality for all variables. A chi-square test was used for categorical variables, while the Mann-Whitney U-test was run for ordinal variables. An independent two-sample $t$-test was used to analyze between-group differences for continuous, normally distributed variables. The $t$-test's effect size was calculated using Cohen $d$, where an effect size value of 0.2 is considered a small effect, of 0.5 is considered a medium effect, and values of 0.8 and above are considered large effects. Pearson's correlations between TAS-20 and TSIA total scores and their dimensions, correlations between TAS-20 and TSIA and correlations of TSIA and TAS-20 with BDI-II and STAI-Y2 respectively, were performed.

All statistical analyses were 2-tailed; $\alpha$ levels were corrected for multiple comparisons using hierarchical Sidak correction. We used two primary measures (TAS-20 and TSIA) for fathers' and mothers' questionnaires respectively, therefore, we had 4 primary variables, and we set $\alpha_{c}<0.013$. Only if the total score is significant, we analyzed the sub-scales for each measure. TAS-20 has 3 sub-scales and TSIA has 6 sub-scales, therefore $\alpha_{c}<0.017$ for the first sub-scales analysis and $\alpha_{c}<0.009$ for the second one. The Eyes Test accuracy and reaction Time were added as secondary measures of the BAP and $\alpha_{c}<0.01$ was set. In the ancillary correlation analyses, we used a similar procedure setting $\alpha_{c}<0.003$ for the correlation among Eyes Test, STAI-Y and BDI-II with TAS-20 and TSIA total 
scores, $\alpha_{c}<0.009$ and $\alpha_{c}<0.004$ for the correlation among Eyes Test, STAI-Y and BDI-II with TAS-20 and TSIA sub-scales.

\section{Results}

Table 1 shows the demographic and clinical characteristics of the sample. Parents of children with and without ASD did not differ as regards to descriptive variables and IQ. Parents on the ASD group were characterized by significantly higher levels of trait anxiety (both for mothers and fathers) and depression (more evident in the mothers) with respect to TD parents. Furthermore, mothers of ASD children were significantly slower than mothers of TD children in recognizing emotions from the eyes. Inter-correlations among TAS-20 and TSIA with their respective subscales were all statistically significant (all $p$-values $<0.001$ ) and correlations ranged from moderate to high (from $r=0.59$ to $r=0.80$ for the TAS-20 and from $r=0.65$ to $r=0.82$ for the TSIA in the ASD parent group and from $r=0.66$ to $r$ $=0.77$ for the TAS-20 and from $r=0.61$ to $r=0.73$ for the TSIA in the TD parent group). The TAS-20 demonstrated also a modest association with the TSIA $(r=0.40 ; p=0.001$ and $\mathrm{r}=0.44 ; p=0.001$ in the ASD and TD parent group respectively), confirming convergent validity of the two measures. On the TAS-20 total score and subscales, no significant between-group difference has been detected, neither in the mothers nor in the fathers (Table 2). Conversely, using the TSIA, we found a significant group difference on the total score, with parents in the ASD group scoring significantly higher (i.e., demonstrating more alexithymia traits) than parents in the TD group ( $p=0.003$ and $p=0.0001$ for mothers and fathers respectively). Furthermore, investigating the TSIA subdomains, mothers on the ASD group scored significantly higher in the "operative thinking $(\mathrm{OT})$ " subscale $(p=0.004)$, while fathers on the ASD group, showed significantly higher scores in all the subscales apart from the "difficulty identifying feelings (DIF)" subscale (all $p$ 's $<0.009$ ). When we analyzed the correlations between the TAS-20 and the TSIA (and their subscales) with the negative effect self-report measures (STAI-Y and the BDI-II) separately in the ASD and TD parent samples, additional significant findings were detected. In the ASD parent group, measures of anxiety and depression were significantly associated to the TAS-20 total scores in both mothers $(\mathrm{r}=0.58, p<0.0001$ and $\mathrm{r}=0.61, p<0.0001$ respectively) and fathers $(\mathrm{r}=0.37, p=0.02$ and $\mathrm{r}=0.36, p=0.03$ respectively). However, in the ASD father group, statistical significance did not survive correction for multiple comparisons. Comparable results were obtained in the TD parent group, with a significant positive association between the TAS-20 total scores and the STAI-Y and BDI-II scores in both mothers $(\mathrm{r}=0.45, p=0.002$ and $\mathrm{r}=0.36$, $p=0.01$ respectively) and fathers $(\mathrm{r}=0.51, p<0.0001$ and $\mathrm{r}=0.31, p=0.03$ respectively). However, in both mothers and fathers, correlations between the TAS-20 and the BDI-II did not survive the threshold for multiple comparisons. Conversely, we did not observe any significant relationship between the TSIA total scores and measures of anxiety and depression in neither group. Correlations between the alexithymia scales (and subscales) and the anxiety and depression measures, corrected for multiple comparisons, are reported in Tables 3 and 4 . As an ancillary analysis, to explore if the group difference on the Eyes Test RT in mothers was driving the group differences found on alexithymia, anxiety, and depression, we analyzed the relationship between these measures in the ASD group. We found no significant correlations between the Eyes Test RT and the other measures (Eyes Test RT vs. TAS-20 total score: $\mathrm{r}=-0.13, p=0.3$; vs. TSIA total score: $\mathrm{r}=-0.12, p=0.4$; vs. STAI-Y: $\mathrm{r}=-0.06, p=0.6$; vs. BDI-II: $\mathrm{r}=-0.16, p=0.2)$. 
Table 1. Descriptive and neuropsychological characteristics in parents of ASD and TD children.

\begin{tabular}{ccccc}
\hline & ASD $(\boldsymbol{n}=\mathbf{5 0})$ & TD $(n=50)$ & $p$-Level & d's Cohen $^{-}$ \\
\hline Age Mother & $38.3 \pm 4.8$ & $39.9 \pm 5.3$ & $0.31^{*}$ & - \\
\hline Age Father & $41.7 \pm 8.4$ & $43.2 \pm 5.2$ & $0.95^{*}$ & - \\
\hline Education Mother & $3[2-5]$ & $5[2-6]$ & $0.05^{\circ}$ & - \\
\hline Education Father & $3[2-6]$ & $3[2-6]$ & $0.66^{\circ}$ & - \\
\hline Verbal IQ Mother & $97.8 \pm 8.9$ & $98.8 \pm 9.9$ & $0.67^{*}$ & 0.11 \\
\hline Performance IQ Mother & $102.1 \pm 12.5$ & $101.7 \pm 13.9$ & $0.91^{*}$ & 0.02 \\
\hline Total IQ Mother & $100.1 \pm 10.3$ & $104.7 \pm 22.7$ & $0.3^{*}$ & 0.26 \\
\hline Verbal IQ Father & $97.9 \pm 8.1$ & $95.6 \pm 8.3$ & $0.31^{*}$ & 0.28 \\
\hline Performance IQ Father & $101.7 \pm 12.2$ & $105.7 \pm 12.2$ & $0.23^{*}$ & 0.32 \\
\hline Total IQ Father & $103.5 \pm 23.8$ & $104.4 \pm 8.4$ & $0.53^{*}$ & 0.05 \\
\hline STAI-Y Mother & $50.3 \pm 10.9$ & $43.9 \pm 7.8$ & $0.002^{*}$ & 0.68 \\
\hline STAI-Y Father & $49.5 \pm 9.6$ & $44.8 \pm 7.9$ & $0.01^{*}$ & 0.54 \\
\hline BDI-II Mother & $11.4 \pm 8.8$ & $7.2 \pm 5.9$ & $0.01^{*}$ & 0.56 \\
\hline BDI-II Father & $7.6 \pm 6.3$ & $4.8 \pm 4.6$ & 0.03 & 0.51 \\
\hline Eyes Test Accuracy Mother & $22.6 \pm 4.2$ & $22.4 \pm 4.4$ & 0.93 & 0.02 \\
\hline Eyes Test RT Mother & $328.3 \pm 185.2$ & $230.2 \pm 82.7$ & 0.005 & 0.68 \\
\hline Eyes Test Accuracy Father & $20.8 \pm 4.1$ & $22.1 \pm 3.5$ & 0.23 & 0.31 \\
\hline Eyes Test RT Father & $257.8 \pm 88.6$ & $247.3 \pm 49.9$ & 0.59 & 0.14 \\
\hline
\end{tabular}

Data are given as mean values (SD), percentage or median [range] as appropriate. ${ }^{\S}$ chi-square test; ${ }^{\circ}=$ Mann-Whitney U-test; ${ }^{*}=$ Two sample $t$-test. ASD, autism spectrum disorders; TD, typical development; education labels, 1 = primary school; 2 = secondary school; 3 = high school; 4 = bachelor degree; $5=$ master degree; IQ, intelligent quotient; STAI-Y, State Trait Anxiety Inventory-Form Y; BDI-II, Beck depression inventory; eyes test accuracy, number of correct answers; eyes test RT, length of time taken to answer in seconds.

Table 2. Alexithymia profile in parents of ASD and TD children.

\begin{tabular}{|c|c|c|c|c|}
\hline & $\frac{\text { ASD }}{(\text { Mean } \pm \text { SD })}$ & $\frac{\text { TD }}{(\text { Mean } \pm \text { SD })}$ & $p$-Level * & $d$ 's Cohen \\
\hline \multicolumn{5}{|c|}{ Toronto Alexithymia Scale (TAS-20) } \\
\hline Total score Mother & $39.6 \pm 12.3$ & $39.1 \pm 9.5$ & 0.79 & 0.05 \\
\hline DIF Mother & $12.1 \pm 5.5$ & $11.4 \pm 4.8$ & 0.53 & 0.13 \\
\hline DDF Mother & $10.3 \pm 4.6$ & $10.3 \pm 4.5$ & 0.97 & 0.01 \\
\hline EOT Mother & $17.5 \pm 4.2$ & $17.1 \pm 4.3$ & 0.65 & 0.09 \\
\hline Total score Father & $42.3 \pm 10.8$ & $40.9 \pm 9.9$ & 0.53 & 0.13 \\
\hline DIF Father & $11.4 \pm 5.2$ & $11.4 \pm 4.7$ & 0.99 & 0.01 \\
\hline DDF Father & $11.4 \pm 4.4$ & $10.6 \pm 9.1$ & 0.38 & 0.11 \\
\hline EOT Father & $19.4 \pm 4.7$ & $19.1 \pm 3.9$ & 0.68 & 0.07 \\
\hline \multicolumn{5}{|c|}{ Toronto Structured Interview for Alexithymia (TSIA) } \\
\hline DIF Mother & $1.6 \pm 1.5$ & $0.9 \pm 0.7$ & 0.02 & 0.6 \\
\hline DDF Mother & $2.2 \pm 2.3$ & $1.6 \pm 1.9$ & 0.22 & 0.29 \\
\hline EOT Mother & $2.9 \pm 1.9$ & $2.1 \pm 1.7$ & 0.04 & 0.44 \\
\hline IMP Mother & $3.8 \pm 1.9$ & $2.7 \pm 2.0$ & 0.02 & 0.56 \\
\hline AA Mother & $3.8 \pm 3.0$ & $2.5 \pm 2.4$ & 0.04 & 0.48 \\
\hline OT Mother & $6.7 \pm 2.9$ & $4.8 \pm 2.5$ & 0.004 & 0.71 \\
\hline Total score Mother & $10.5 \pm 4.6$ & $7.3 \pm 4.4$ & 0.003 & 0.71 \\
\hline DIF Father & $2.3 \pm 2.6$ & $1.0 \pm 1.6$ & 0.04 & 0.6 \\
\hline DDF Father & $3.8 \pm 3.3$ & $1.3 \pm 1.5$ & 0.001 & 0.97 \\
\hline EOT Father & $4.2 \pm 2.8$ & $2.3 \pm 1.5$ & 0.006 & 0.85 \\
\hline IMP Father & $4.2 \pm 2.3$ & $2.1 \pm 1.2$ & 0.001 & 1.15 \\
\hline AA Father & $5.9 \pm 5.3$ & $2.3 \pm 2.4$ & 0.004 & 0.87 \\
\hline OT Father & $8.5 \pm 4.5$ & $4.4 \pm 2.1$ & 0.0001 & 1.16 \\
\hline Total score Father & $14.9 \pm 9.1$ & $6.7 \pm 3.7$ & 0.0001 & 1.19 \\
\hline
\end{tabular}

DIF, difficulty identifying feelings; DDF, difficulty describing feelings (DDF); OT, externally-oriented thinking; IMP, imaginal processing; AA, affect awareness; OT, operative thinking. * $\alpha$ levels are corrected for multiple comparisons using hierarchical Sidak correction. An $\alpha_{c}<0.01$ was set for the TAS-20 total score and subscales and for the TSIA total score and an $\alpha_{c}<0.009$ was set for the TSIA subscales. 
Table 3. Correlations between alexithymia scales, trait anxiety, and depression in parents of ASD children.

\begin{tabular}{|c|c|c|c|c|}
\hline \multirow{2}{*}{ ASD Parent Group } & STAI-Y & STAI-Y & \multirow{2}{*}{ BDI-II Mother } & \multirow{2}{*}{ BDI-II Father } \\
\hline & Mother & Father & & \\
\hline \multicolumn{5}{|c|}{ Toronto Alexithymia Scale (TAS-20) } \\
\hline \multirow{2}{*}{ Total score Mother } & $r=0.58$ & & $r=0.61$ & \\
\hline & $p<0.0001$ & & $p<0.0001$ & \\
\hline \multirow{2}{*}{ DIF Mother } & $r=0.67$ & & $r=0.73$ & \\
\hline & $p<0.0001$ & & $p<0.0001$ & \\
\hline \multirow{2}{*}{ DDF Mother } & $r=0.46$ & & $r=0.54$ & \\
\hline & $p=0.002$ & & $p<0.0001$ & \\
\hline \multirow{2}{*}{ EOT Mother } & $r=0.09$ & & $r=0.21$ & \\
\hline & $p=0.54$ & & $p=0.19$ & \\
\hline \multirow{2}{*}{ Total score Father } & & $r=0.37$ & & $r=0.36$ \\
\hline & & $p=0.02$ & & $p=0.03$ \\
\hline \multirow{2}{*}{ DIF Father } & & $r=0.32$ & & $r=0.45$ \\
\hline & & $p=0.04$ & & $p=0.005$ \\
\hline \multirow{2}{*}{ DDF Father } & & $r=0.33$ & & $r=0.21$ \\
\hline & & $p=0.04$ & & $p=0.21$ \\
\hline \multirow{2}{*}{ EOT Father } & & $r=0.18$ & & $r=0.13$ \\
\hline & & $p=0.27$ & & $p=0.43$ \\
\hline \multicolumn{5}{|c|}{ Toronto Structured Interview for Alexithymia (TSIA) } \\
\hline \multirow{2}{*}{ Total score Mother } & $r=0.11$ & & $r=0.15$ & \\
\hline & $p=0.51$ & & $p=0.35$ & \\
\hline \multirow{2}{*}{ DIF Mother } & $r=0.31$ & & $r=0.25$ & \\
\hline & $p=0.07$ & & $p=0.13$ & \\
\hline \multirow{2}{*}{ DDF Mother } & $r=0.11$ & & $r=0.11$ & \\
\hline & $p=0.52$ & & $p=0.49$ & \\
\hline \multirow{2}{*}{ EOT Mother } & $r=0.15$ & & $r=0.21$ & \\
\hline & $p=0.39$ & & $p=0.22$ & \\
\hline \multirow{2}{*}{ IMP Mother } & $r=0.24$ & & $r=0.17$ & \\
\hline & $p=0.15$ & & $p=0.32$ & \\
\hline \multirow{2}{*}{ AA Mother } & $r=0.23$ & & $r=0.22$ & \\
\hline & $p=0.16$ & & $p=0.19$ & \\
\hline \multirow{2}{*}{ OT Mother } & $r=0.07$ & & $r=0.35$ & \\
\hline & $p=0.07$ & & $p=0.04$ & \\
\hline \multirow{2}{*}{ Total score Father } & & $r=0.13$ & & $r=0.17$ \\
\hline & & $p=0.51$ & & $p=0.36$ \\
\hline \multirow{2}{*}{ DIF Father } & & $r=0.07$ & & $r=0.25$ \\
\hline & & $p=0.7$ & & $p=0.19$ \\
\hline \multirow{2}{*}{ DDF Father } & & $r=0.38$ & & $r=0.08$ \\
\hline & & $p=0.04$ & & $p=0.68$ \\
\hline & & $r=0.21$ & & $r=0.03$ \\
\hline EOT Father & & $p=0.28$ & & $p=0.88$ \\
\hline IMP Father & & $r=0.05$ & & $R=-0.26$ \\
\hline IIVP Father & & $p=0.81$ & & $p=0.18$ \\
\hline A A Father & & $r=0.28$ & & $r=0.05$ \\
\hline AA ratner & & $p=0.13$ & & $p=0.81$ \\
\hline OT Father & & $r=0.11$ & & $R=-0.17$ \\
\hline 11 Father & & $p=0.59$ & & $p=0.41$ \\
\hline
\end{tabular}

DIF, difficulty identifying feelings; DDF, difficulty describing feelings (DDF); OT, externally-oriented thinking; IMP, imaginal processing; AA, affect awareness; OT: operative thinking. ${ }^{*} \alpha$ levels were corrected for multiple comparisons using hierarchical Sidak correction. We set an $\alpha_{c}<0.006$ for the correlation among STAI-Y and BDI-II with TAS-20 and TSIA total scores and an $\alpha_{c}<0.009$ for the correlation among STAI-Y and BDI-II with TAS-20 and TSIA subscales. 
Table 4. Correlations between alexithymia scales, trait anxiety, and depression in parents of TD children.

\begin{tabular}{|c|c|c|c|c|}
\hline \multirow{2}{*}{ TD Parent Group } & STAI-Y & STAI-Y & \multirow{2}{*}{ BDI-II Mother } & \multirow{2}{*}{ BDI-II Father } \\
\hline & Mother & Father & & \\
\hline \multicolumn{5}{|c|}{ Toronto Alexithymia Scale (TAS-20) } \\
\hline \multirow{2}{*}{ Total score Mother } & $r=0.45$ & & $r=0.36$ & \\
\hline & $p=0.002$ & & $p=0.01$ & \\
\hline \multirow{2}{*}{ DIF Mother } & $r=0.37$ & & $r=0.28$ & \\
\hline & $p=0.008$ & & $p=0.06$ & \\
\hline \multirow{2}{*}{ DDF Mother } & $r=0.35$ & & $r=0.26$ & \\
\hline & $p=0.01$ & & $p=0.07$ & \\
\hline \multirow{2}{*}{ EOT Mother } & $r=0.11$ & & $r=0.21$ & \\
\hline & $p=0.43$ & & $p=0.15$ & \\
\hline \multirow{2}{*}{ Total score Father } & & $r=0.51$ & & $r=0.31$ \\
\hline & & $p<0.0001$ & & $p=0.03$ \\
\hline \multirow{2}{*}{ DIF Father } & & $r=0.42$ & & $r=0.4$ \\
\hline & & $p=0.003$ & & $p=0.007$ \\
\hline \multirow{2}{*}{ DDF Father } & & $r=0.45$ & & $r=0.39$ \\
\hline & & $p=0.002$ & & $p=0.007$ \\
\hline \multirow{2}{*}{ EOT Father } & & $r=0.41$ & & $r=0.11$ \\
\hline & & $p=0.004$ & & $p=0.47$ \\
\hline \multicolumn{5}{|c|}{ Toronto Structured Interview for Alexithymia (TSIA) } \\
\hline \multirow{2}{*}{ Total score Mother } & $r=0.43$ & & $r=0.45$ & \\
\hline & $p=0.01$ & & $p=0.007$ & \\
\hline \multirow{2}{*}{ DIF Mother } & $r=0.29$ & & $r=0.43$ & \\
\hline & $p=0.1$ & & $p=0.01$ & \\
\hline \multirow{2}{*}{ DDF Mother } & $r=0.28$ & & $r=0.39$ & \\
\hline & $p=0.11$ & & $p=0.02$ & \\
\hline \multirow{2}{*}{ EOT Mother } & $r=0.42$ & & $r=0.41$ & \\
\hline & $p=0.01$ & & $p=0.02$ & \\
\hline \multirow{2}{*}{ IMP Mother } & $r=0.19$ & & $r=0.005$ & \\
\hline & $p=0.28$ & & $p=0.98$ & \\
\hline \multirow{2}{*}{ AA Mother } & $r=0.32$ & & $r=0.45$ & \\
\hline & $p=0.06$ & & $p=0.008$ & \\
\hline \multirow{2}{*}{ OT Mother } & $r=0.43$ & & $r=0.35$ & \\
\hline & $p=0.01$ & & $p=0.04$ & \\
\hline \multirow{2}{*}{ Total score Father } & & $r=0.42$ & & $r=0.36$ \\
\hline & & $p=0.04$ & & $p=0.09$ \\
\hline \multirow{2}{*}{ DIF Father } & & $r=0.39$ & & $r=0.43$ \\
\hline & & $p=0.06$ & & $p=0.04$ \\
\hline \multirow{2}{*}{ DDF Father } & & $r=0.4$ & & $r=0.25$ \\
\hline & & $p=0.05$ & & $p=0.25$ \\
\hline EOT Enther & & $r=0.03$ & & $r=0.02$ \\
\hline EOT Father & & $p=0.87$ & & $p=0.92$ \\
\hline JMP Fethor & & $r=0.21$ & & $r=0.19$ \\
\hline IMP Father & & $p=0.34$ & & $p=0.37$ \\
\hline 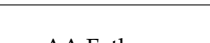 & & $r=0.51$ & & $r=0.44$ \\
\hline AA Father & & $p=0.01$ & & $p=0.03$ \\
\hline OT Father & & $r=0.15$ & & $r=0.13$ \\
\hline OH Father & & $p=0.49$ & & $p=0.54$ \\
\hline
\end{tabular}

DIF, difficulty identifying feelings; DDF, difficulty describing feelings (DDF); OT, externally-oriented thinking; IMP, imaginal processing; AA, affect awareness; OT, operative thinking. ${ }^{*} \alpha$ levels were corrected for multiple comparisons using hierarchical Sidak correction. We set an $\alpha_{c}<0.006$ for the correlation among STAI-Y and BDI-II with TAS-20 and TSIA total scores and an $\alpha_{c}<0.009$ for the correlation among STAI-Y and BDI-II with TAS-20 and TSIA subscales. 


\section{Discussion}

In our study, we explored the construct of alexithymia in parents of children with and without ASD using a multi-method approach based on self-rated and external rater assessment. Both the TAS-20 and the TSIA were administered to all the participants showing that the TSIA but not the TAS-20 was able to detect significant group differences in alexithymia traits among parents of children with and without ASD, with parents of ASD children displaying significantly higher levels of alexithymia as reflected by the total score and the subscale scores, especially for fathers. This result suggests that the assessment method has an impact on the capacity to detect alexithymic traits in subclinical populations such as parents of ASD children. The TAS-20, in fact, implies that people are aware and able to identify and describe their own feelings and strongly relies on the self-perception of the subject. Individuals with higher alexithymia traits may lack awareness of their own difficulties because of their meta-emotional impairment [65], and a structured interview such as the TSIA may possibly avoid this bias, as the examiner can use probes and examples to more in-depth assess the presence and degree of alexithymia. This result is in line with previous evidence, in a different clinical sample, reporting that parents of anorexic daughters display significantly higher alexithymia traits at the TSIA as compared to the TAS-20 [54]. Furthermore, we explored the dimensions of negative affect and trait anxiety in our sample of parents, and in agreement with previous studies, we found significantly higher levels of self-reported trait anxiety and depression in parents of children with ASD (both in mothers and fathers), compared with parents of TD children. Last but not least, we analyzed the correlation between measures of alexithymia and self-report measures of depression and trait anxiety to investigate if negative affect may influence rater's answers to the TAS-20. We found that the TAS-20 total score and the subscales "difficulty identifying feelings (DIF)" and "difficulty describing feelings (DDF)", but not the TSIA total and subscale scores, were strongly associated with measures of both anxiety and depression in mothers of ASD children. Similar results were observed in the TD parent group, with the TAS-20 being strongly associated with anxiety traits and depression, especially in fathers, and the TSIA showing no significant correlations (apart from the subscale "affect awareness" which was associated with depression in mothers). These findings may suggest that symptoms related to negative emotional states such as reduced cognitive flexibility, emotional awareness, and affective range may influence self-rated responses on the TAS-20. Co-occurring anxiety and depression, in fact, may affect the way one's emotions are self-judged and instead, having a structured interview such as the TSIA, may ensure a more objective and reliable assessment of the facets related to alexithymia reducing the potential misinterpretation of one's emotional state due to self-judgment in relation to negative affect. In line with our results, previous evidence reported that negative affectivity influences the rater's self-report on the TAS-20 items, especially on the DIF and DDF factor subscales, while no association between the TSIA scores and scores at the STAI-Y and the DBI-II was found $[46,49,53]$.

Finally, to explore if aspects of the broader autism phenotype (BAP) in the ASD parent group would account for the results obtained on the alexithymia and negative affect dimensions, we used the Eyes Test to measure emotion recognition and Theory of Mind (ToM) abilities in both groups. Previous evidence, reported impairment in emotion recognition at the Eyes Test in parents of ASD children [66]. We found that mothers of ASD children were significantly slower than mothers of TD children in detecting emotional, mental states from eyes, but no relationship between this measure and measures of alexithymia, anxiety, and depression was found, suggesting that in our ASD parent sample, atypical empathy is not associated to alexithymia traits nor to negative affectivity. Our results, in the light of the mixed findings reported in the literature about the influence of alexithymia on atypical empathy $[17,25,67]$, clearly indicate that measuring these two constructs in relation to autism traits is not simple and generalization from clinical samples to sub-clinical samples such as parents of ASD children to the general population poses complex conceptual and methodological issues that should be taken into account.

Some limitations should be considered with regard to the study and the use of the TSIA. Firstly, the study sample size was relatively small, although rigorously selected according to precise inclusion and 
exclusion criteria to avoid sampling bias; furthermore, there was no opportunity to conduct a specific psychometric and clinical evaluation on the TD children, to exclude not diagnosed neuropsychiatric conditions, which may have influenced the responses in the TD parent group. Finally, in relation to the use of the TSIA, it should be considered that the time needed to complete the interview, as well as the need for appropriate training in administration procedures and scoring, make the use of the TSIA still limited and more difficult in clinical practice. Further studies are warranted to replicate these results and to generalize these findings from clinical samples to the general population.

\section{Conclusions}

Our study explored the construct of alexithymia in parents of children with and without ASD using a multi-method approach, and also investigated the correlation between the alexithymia construct, trait anxiety, and depression within the broader autism phenotype (BAP). Based on our findings, in subclinical populations such as parents of children with ASD, the use of an external-rater assessment should be considered to allow a more accurate detection of the presence and degree of alexithymia and to disentangle potential influences of negative affect states and trait anxiety on the alexithymia dimension.

Author Contributions: E.L. participated in the study design, enrolled and tested the participants and contributed to the manuscript draft. L.R. designed and supervised the study and drafted the manuscript. A.C. conducted the statistical analysis and participated in the manuscript draft. F.M., F.I.F., C.C., L.S., S.B., and R.S. helped with participants' enrollment and contributed with data interpretation. D.V. and G.T. contributed with statistical analysis and statistical data interpretations. G.P. contributed in the coordination of the study. All authors read and approved the final manuscript.

Funding: This research was partially supported by the grant from the Sicilian Region of Italy (Assessorato Regionale dell'Istruzione e della Formazione Professionale, Avviso 11/2017 Rafforzare l'occupabilità nel sistema R\&S e la nascita di spin off di ricerca in Sicilia-P.O. FSE 2014/2020, project no. 2014.IT.05.SFOP.014/3/10.4/9.2.10/0011—CUP G47B17000100009, entitled SANi) and partially supported by the grant from Azienda Sanitaria Provinciale di Catania (deliberations no. 2005 24/06/2016 and no. 3304 04/10/2017).

Acknowledgments: We acknowledge all the parents who volunteered to participate in the study.

Conflicts of Interest: All authors declare no potential conflicts of interest, including any financial, personal or other relationships with other people or organizations relevant to the subject of their manuscript.

\section{References}

1. Eccleston, D. Disorders of Affect Regulation: Alexithymia in Medical and Psychiatric Illness; Taylor, G.J., Bagby, R.M., Parker, J.D.A., Eds.; Cambridge University Press: Cambridge, UK, 1998; ISBN 0-521-45610-X.

2. Franz, M.; Popp, K.; Schaefer, R.; Sitte, W.; Schneider, C.; Hardt, J.; Decker, O.; Braehler, E. Alexithymia in the German general population. Soc. Psychiatry Psychiatr. Epidemiol. 2008, 43, 54-62. [CrossRef] [PubMed]

3. Taylor, G.J.; Michael Bagby, R.; Parker, J.D.A. The Alexithymia Construct: A Potential Paradigm for Psychosomatic Medicine. Psychosomatics 1991, 32, 153-164. [CrossRef]

4. Parker, J.D.A.; Taylor, G.J.; Bagby, R.M. The 20-Item Toronto Alexithymia Scale. J. Psychosom. Res. 2003, 55, 269-275. [CrossRef]

5. Picardi, A.; Toni, A.; Caroppo, E. Stability of Alexithymia and Its Relationships with the 'Big Five' Factors, Temperament, Character, and Attachment Style. Psychother. Psychosom. 2005, 74, 371-378. [CrossRef] [PubMed]

6. Vermeulen, N.; Luminet, O.; Corneille, O. Alexithymia and the automatic processing of affective information: Evidence from the affective priming paradigm. Cogn. Emot. 2006, 20, 64-91. [CrossRef]

7. Connelly, M.; Denney, D.R. Regulation of emotions during experimental stress in alexithymia. J. Psychosom. Res. 2007, 62, 649-656. [CrossRef] [PubMed]

8. FeldmanHall, O.; Dalgleish, T.; Mobbs, D. Alexithymia decreases altruism in real social decisions. Cortex 2013, 49, 899-904. [CrossRef] [PubMed]

9. Baron-Cohen, S.; Wheelwright, S. The Empathy Quotient: An Investigation of Adults with Asperger Syndrome or High Functioning Autism, and Normal Sex Differences. J. Autism Dev. Disord. 2004, 34, 163-175. [CrossRef] 
10. Auyeung, B.; Baron-Cohen, S.; Ashwin, E.; Knickmeyer, R.; Taylor, K.; Hackett, G. Fetal testosterone and autistic traits. Br. J. Psychol. 2009, 100, 1-22. [CrossRef]

11. Lombardo, M.V.; Barnes, J.L.; Wheelwright, S.J.; Baron-Cohen, S. Self-Referential Cognition and Empathy in Autism. PLoS ONE 2007, 2, e883. [CrossRef] [PubMed]

12. Sucksmith, E.; Allison, C.; Baron-Cohen, S.; Chakrabarti, B.; Hoekstra, R.A. Empathy and emotion recognition in people with autism, first-degree relatives, and controls. Neuropsychologia 2013, 51, 98-105. [CrossRef] [PubMed]

13. Aaron, R.V.; Benson, T.L.; Park, S. Investigating the role of alexithymia on the empathic deficits found in schizotypy and autism spectrum traits. Pers. Individ. Dif. 2015, 77, 215-220. [CrossRef]

14. American Psychiatric Association. DSM-5 Diagnostic Classification. In Diagnostic and Statistical Manual of Mental Disorders; American Psychiatric Association: Washington, DC, USA, 2013.

15. Hill, E.; Berthoz, S.; Frith, U. Brief Report: Cognitive Processing of Own Emotions in Individuals with Autistic Spectrum Disorder and in Their Relatives. J. Autism Dev. Disord. 2004, 34, 229-235. [CrossRef] [PubMed]

16. Berthoz, S.; Hill, E.L. The validity of using self-reports to assess emotion regulation abilities in adults with autism spectrum disorder. Eur. Psychiatry 2005, 20, 291-298. [CrossRef] [PubMed]

17. Cook, R.; Brewer, R.; Shah, P.; Bird, G. Alexithymia, Not Autism, Predicts Poor Recognition of Emotional Facial Expressions. Psychol. Sci. 2013, 24, 723-732. [CrossRef]

18. Griffin, C.; Lombardo, M.V.; Auyeung, B. Alexithymia in children with and without autism spectrum disorders. Autism Res. 2016, 9, 773-780. [CrossRef]

19. Gaigg, S.B.; Cornell, A.S.F.; Bird, G. The psychophysiological mechanisms of alexithymia in autism spectrum disorder. Autism 2018, 22, 227-231. [CrossRef]

20. Kinnaird, E.; Stewart, C.; Tchanturia, K. Investigating alexithymia in autism: A systematic review and meta-analysis. Eur. Psychiatry 2019, 55, 80-89. [CrossRef]

21. Poquérusse, J.; Pastore, L.; Dellantonio, S.; Esposito, G. Alexithymia and Autism Spectrum Disorder: A Complex Relationship. Front. Psychol. 2018, 9, 1-10. [CrossRef]

22. Bird, G.; Cook, R. Mixed emotions: The contribution of alexithymia to the emotional symptoms of autism. Transl. Psychiatry 2013, 3, e285. [CrossRef]

23. Shah, P.; Hall, R.; Catmur, C.; Bird, G. Alexithymia, not autism, is associated with impaired interoception. Cortex 2016, 81, 215-220. [CrossRef] [PubMed]

24. Livingston, L.A.; Livingston, L.M. Commentary: Alexithymia, not autism, is associated with impaired interoception. Front. Psychol. 2016, 7, 7-9. [CrossRef] [PubMed]

25. Shah, P.; Livingston, L.A.; Callan, M.J.; Player, L. Trait Autism is a Better Predictor of Empathy than Alexithymia. J. Autism Dev. Disord. 2019, 49, 3956-3964. [CrossRef] [PubMed]

26. Berthoz, S.; Lalanne, C.; Crane, L.; Hill, E.L. Investigating emotional impairments in adults with autism spectrum disorders and the broader autism phenotype. Psychiatry Res. 2013, 208, 257-264. [CrossRef]

27. Bailey, A.; Le Couteur, A.; Gottesman, I.; Bolton, P.; Simonoff, E.; Yuzda, E.; Rutter, M. Autism as a strongly genetic disorder: Evidence from a British twin study. Psychol. Med. 1995, 25, 63-77. [CrossRef]

28. Bolton, P.; Macdonald, H.; Pickles, A.; Rios, P.; Goode, S.; Crowson, M.; Bailey, A.; Rutter, M. A Case-Control Family History Study of Autism. J. Child Psychol. Psychiatry 1994, 35, 877-900. [CrossRef]

29. Piven, J.; Palmer, P.; Jacobi, D.; Childress, D.; Arndt, S. Broader autism phenotype: Evidence from a family history study of multiple-incidence autism families. Am. J. Psychiatry 1997, 154, 185-190. [CrossRef] [PubMed]

30. Piven, J. The broad autism phenotype: A complementary strategy for molecular genetic studies of autism. Am. J. Med. Genet. 2001, 105, 34-35. [CrossRef]

31. Szatmari, P.; MacLean, J.E.; Jones, M.B.; Bryson, S.E.; Zwaigenbaum, L.; Bartolucci, G.; Mahoney, W.J.; Tuff, L. The Familial Aggregation of the Lesser Variant in Biological and Nonbiological Relatives of PDD Probands: A Family History Study. J. Child Psychol. Psychiatry 2000, 41, 579-586. [CrossRef]

32. Landa, R.; Piven, J.; Wzorek, M.M.; Gayle, J.O.; Chase, G.A.; Folstein, S.E. Social language use in parents of autistic individuals. Psychol. Med. 1992, 22, 245-254. [CrossRef]

33. Piven, J.; Wzorek, M.; Landa, R.; Lainhart, J.; Bolton, P.; Chase, G.A.; Folstein, S. Personality characteristics of the parents of autistic individuals. Psychol. Med. 1994, 24, 783-795. [CrossRef] [PubMed] 
34. Hurley, R.S.E.; Losh, M.; Parlier, M.; Reznick, J.S.; Piven, J. The Broad Autism Phenotype Questionnaire. J. Autism Dev. Disord. 2007, 37, 1679-1690. [CrossRef] [PubMed]

35. Wolff, S.; Narayan, S.; Moyes, B. Personality Characteristics of Parents of Autistic Children: A Controlled Study. J. Child Psychol. Psychiatry 1988, 29, 143-153. [CrossRef]

36. Murphy, M.; Bolton, P.F.; Pickles, A.; Fombonne, E.; Piven, J.; Rutter, M. Personality traits of the relatives of autistic probands. Psychol. Med. 2000, 30, 1411-1424. [CrossRef]

37. Yirmiya, N.; Shaked, M. Psychiatric disorders in parents of children with autism: A meta-analysis. J. Child Psychol. Psychiatry 2005, 46, 69-83. [CrossRef]

38. Papageorgiou, V.; Georgiades, S.; Mavreas, V. Brief report: Cross-cultural evidence for the heterogeneity of the restricted, repetitive behaviours and interests domain of autism: A Greek study. J. Autism Dev. Disord. 2008, 38, 558-561. [CrossRef]

39. Bagby, R.M.; Parker, J.D.A.; Taylor, G.J. The twenty-item Toronto Alexithymia scale-I. Item selection and cross-validation of the factor structure. J. Psychosom. Res. 1994, 38, 23-32. [CrossRef]

40. Bagby, R.M.; Parker, J.D.A.; Taylor, G.J. Twenty-five years with the 20-item Toronto Alexithymia Scale. J. Psychosom. Res. 2020, 131, 109940. [CrossRef] [PubMed]

41. Lane, R.D.; Weihs, K.L.; Herring, A.; Hishaw, A.; Smith, R. Affective agnosia: Expansion of the alexithymia construct and a new opportunity to integrate and extend Freud's legacy. Neurosci. Biobehav. Rev. 2015, 55, 594-611. [CrossRef]

42. Luminet, O.; Taylor, G.; Bagby, R. Assessment of alexithymia: Self-report and observer-rated measures. In The Handbook of Emotional Intelligence: Theory, Development, Assessment, and Application at Home, School, and in the Workplace; Bar-On, R., Parker, J.D.A., Eds.; Jossey-Bass: San Francisco, CA, USA, 2000; pp. 301-319.

43. Meganck, R.; Vanheule, S.; Desmet, M. Factorial Validity and Measurement Invariance of the 20-Item Toronto Alexithymia Scale in Clinical and Nonclinical Samples. Assessment 2008, 15, 36-47. [CrossRef]

44. Mikhailova, E.S.; Vladimirova, T.V.; Iznak, A.F.; Tsusulkovskaya, E.J.; Sushko, N.V. Abnormal recognition of facial expression of emotions in depressed patients with major depression disorder and schizotypal personality disorder. Biol. Psychiatry 1996, 40, 697-705. [CrossRef]

45. Leising, D.; Grande, T.; Faber, R. The Toronto Alexithymia Scale (TAS-20): A measure of general psychological distress. J. Res. Pers. 2009, 43, 707-710. [CrossRef]

46. Lumley, M.A. Alexithymia and negative emotional conditions. J. Psychosom. Res. 2000, 49, 51-54. [CrossRef]

47. Marchesi, C.; Giaracuni, G.; Paraggio, C.; Ossola, P.; Tonna, M.; De Panfilis, C. Pre-morbid alexithymia in panic disorder: A cohort study. Psychiatry Res. 2014, 215, 141-145. [CrossRef] [PubMed]

48. Bagby, R.M.; Taylor, G.J.; Parker, J.D.A.; Dickens, S.E. The development of the Toronto structured interview for Alexithymia: Item selection, factor structure, reliability and concurrent validity. Psychother. Psychosom. 2006. [CrossRef]

49. Caretti, V.; Porcelli, P.; Solano, L.; Schimmenti, A.; Bagby, R.M.; Taylor, G.J. Reliability and validity of the Toronto Structured Interview for Alexithymia in a mixed clinical and nonclinical sample from Italy. Psychiatry Res. 2011, 187, 432-436. [CrossRef]

50. Grabe, H.J.; Löbel, S.; Dittrich, D.; Bagby, R.M.; Taylor, G.J.; Quilty, L.C.; Spitzer, C.; Barnow, S.; Mathier, F.; Jenewein, J.; et al. The German version of the Toronto Structured Interview for Alexithymia: Factor structure, reliability, and concurrent validity in a psychiatric patient sample. Compr. Psychiatry 2009, 50, 424-430. [CrossRef] [PubMed]

51. Inslegers, R.; Meganck, R.; Ooms, E.; Vanheule, S.; Taylor, G.J.; Bagby, R.M.; De Fruyt, F.; Desmet, M. The Dutch Language Version of the Toronto Structured Interview for Alexithymia: Reliability, Factor Structure and Concurrent Validity. Psychol. Belg. 2013, 53, 93. [CrossRef]

52. Rosenberg, N.; Rufer, M.; Lichev, V.; Ihme, K.; Grabe, H.J.; Kugel, H.; Kersting, A.; Suslow, T. Observer-Rated Alexithymia and its Relationship with the Five-Factor-Model of Personality. Psychol. Belg. 2016, 56, 118-134. [CrossRef] [PubMed]

53. Montebarocci, O.; Surcinelli, P. Correlations between TSIA and TAS-20 and their relation to self-reported negative affect: A study using a multi-method approach in the assessment of alexithymia in a nonclinical sample from Italy. Psychiatry Res. 2018, 270, 187-193. [CrossRef]

54. Mannarini, S.; Nacinovich, R.; Bomba, M.; Balottin, L. Alexithymia in parents and adolescent anorexic daughters: Comparing the responses to TSIA and TAS-20 scales. Neuropsychiatr. Dis. Treat. 2014, 10, 1941-1951. [CrossRef] [PubMed] 
55. Piven, J.; Chase, G.A.; Landa, R.; Wzorek, M.; Gayle, J.; Cloud, D.; Folstein, S. Psychiatric Disorders in the Parents of Autistic Individuals. J. Am. Acad. Child Adolesc. Psychiatry 1991, 30, 471-478. [CrossRef] [PubMed]

56. Bitsika, V.; Sharpley, C.F. Stress, Anxiety and Depression Among Parents of Children With Autism Spectrum Disorder. Aust. J. Guid. Couns. 2004, 14, 151-161. [CrossRef]

57. Hamlyn-Wright, S.; Draghi-Lorenz, R.; Ellis, J. Locus of control fails to mediate between stress and anxiety and depression in parents of children with a developmental disorder. Autism 2007, 11, 489-501. [CrossRef] [PubMed]

58. Kuusikko-Gauffin, S.; Pollock-Wurman, R.; Mattila, M.-L.; Jussila, K.; Ebeling, H.; Pauls, D.; Moilanen, I. Social Anxiety in Parents of High-Functioning Children with Autism and Asperger Syndrome. J. Autism Dev. Disord. 2013, 43, 521-529. [CrossRef]

59. Al-Farsi, O.; Al-Farsi, Y.; Al-Sharbati, M.; Al-Adawi, S. Stress, anxiety, and depression among parents of children with autism spectrum disorder in Oman: A case-control study. Neuropsychiatr. Dis. Treat. 2016, 12, 1943-1951. [CrossRef]

60. Schnabel, A.; Youssef, G.J.; Hallford, D.J.; Hartley, E.J.; McGillivray, J.A.; Stewart, M.; Forbes, D.; Austin, D.W. Psychopathology in parents of children with autism spectrum disorder: A systematic review and meta-analysis of prevalence. Autism 2020, 24, 26-40. [CrossRef]

61. Beck, A.T.; Steer, R.A.; Brown, G.K. Manual for the Beck Depression Inventory-II; Psychological Corporation: San Antonio, TX, USA, 1996; ISBN 0158018389.

62. Sica, C.; Ghisi, M. The Italian versions of the Beck Anxiety Inventory and the Beck Depression Inventory-II: Psychometric Properties and Discriminant Power; Lange, M.A., Ed.; Nova Science: Hauppauge, NY, USA, 2007; ISBN 1-60021-571-8 (Hardcover), 978-1-60021-571-1 (Hardcover).

63. Baron-Cohen, S.; Wheelwright, S.; Hill, J.; Raste, Y.; Plumb, I. The "Reading the Mind in the Eyes" Test revised version: A study with normal adults, and adults with Asperger syndrome or high-functioning autism. J. Child Psychol. Psychiatry. 2001, 42, 241-251. [CrossRef]

64. Wechsler, D. Wechsler Abbreviated Scale of Intelligence-Second Edition (WASI-II); NCS Pearson: San Antonio, TX, USA, 2011.

65. Lundh, L.-G.; Johnsson, A.; Sundqvist, K.; Olsson, H. Alexithymia, memory of emotion, emotional awareness, and perfectionism. Emotion 2002, 2, 361-379. [CrossRef]

66. Baron-Cohen, S.; Hammer, J. Parents of Children with Asperger Syndrome: What is the Cognitive Phenotype? J. Cogn. Neurosci. 1997, 9, 548-554. [CrossRef]

67. Oakley, B.F.M.; Brewer, R.; Bird, G.; Catmur, C. Theory of mind is not theory of emotion: A cautionary note on the reading the mind in the eyes test. J. Abnorm. Psychol. 2016, 125, 818-823. [CrossRef] [PubMed] 